\title{
Specification of Distinct Dopaminergic Neural Pathways: Roles of the Eph Family Receptor EphB1 and Ligand Ephrin-B2
}

\author{
Yong Yue, ${ }^{1}$ David A. J. Widmer, ${ }^{2}$ Alycia K. Halladay, ${ }^{2}$ Douglas Pat Cerretti, ${ }^{3}$ George C. Wagner, ${ }^{2}$ \\ Jean-Luc Dreyer, ${ }^{4}$ and Renping Zhou ${ }^{1}$ \\ ${ }^{1}$ Laboratory for Cancer Research, College of Pharmacy, and 2Department of Psychology, Rutgers University, Piscataway, \\ New Jersey 08855, 3/mmunex Corporation, Seattle, Washington 98101, and 4Department of Biochemistry, University of \\ Fribourg, 1700 Fribourg, Switzerland
}

\begin{abstract}
Dopaminergic neurons in the substantia nigra and ventral tegmental area project to the caudate putamen and nucleus accumbens/olfactory tubercle, respectively, constituting mesostriatal and mesolimbic pathways. The molecular signals that confer target specificity of different dopaminergic neurons are not known. We now report that EphB1 and ephrin-B2, a receptor and ligand of the Eph family, are candidate guidance molecules for the development of these distinct pathways. EphB1 and ephrin-B2 are expressed in complementary patterns in the midbrain dopaminergic neurons and their targets, and the ligand specifically inhibits the growth of neurites and induces the
\end{abstract}

The midbrain dopaminergic neurons are located primarily in two adjacent regions, the more lateral substantia nigra and the more medial ventral tegmental area, and project to the forebrain, forming several distinct pathways (Ungerstedt, 1971; Moore and Bloom, 1978; Lindvall and Bjorklund, 1983; Di Chiara et al., 1992; Heimer et al., 1995). Ventral tegmental dopaminergic neurons send their axons to the ventromedial striatum (which includes nucleus accumbens and olfactory tubercle), constituting the mesolimbic pathway, and to the cortex (mesocortical pathway) (Simon et al., 1976, 1979; Nauta et al., 1978; Beckstead et al., 1979). In contrast, substantia nigra dopaminergic neurons selectively project to dorsolateral striatum (caudate putamen) in an orderly medial-to-lateral arrangement, forming the nigrostriatal pathway (Carter and Fibiger, 1977; Fallon et al., 1978; Nauta et al., 1978; Beckstead et al., 1979; van der Kooy, 1979). Although these pathways have been identified for nearly three decades, the underlying molecular mechanisms for the development of these distinct pathways are still unknown.

The Eph family receptor tyrosine kinases and their ligands have been implicated in guiding axons during the development of the nervous system (for review, see Harris and Holt, 1995; Tessier-Lavigne, 1995; Friedman and O'Leary, 1996; Orioli and Klein, 1997; Pasquale, 1997; Flanagan and Vanderhaeghen, 1998; Zhou, 1998). The Eph family is the largest known group of receptor tyrosine kinases, including at least eight ligands and 14

\footnotetext{
Received July 16, 1998; revised Nov. 23, 1998; accepted Dec. 22, 1998.

This research was funded by the National Institute on Drug Abuse (Grant 1RO1DA11480-01) and by an Exploratory Research grant from the National Institute of Environmental and Occupational Health Sciences. We thank W. Schultz for the critical reading of this manuscript.

Correspondence should be addressed to Dr. Renping Zhou, Laboratory for Cancer Research, Department of Chemical Biology, College of Pharmacy, Rutgers University, Piscataway, NJ 08855.

Copyright (C) 1999 Society for Neuroscience $\quad 0270-6474 / 99 / 192090-12 \$ 05.00 / 0$
}

cell loss of substantia nigra, but not ventral tegmental, dopaminergic neurons. These studies suggest that the ligand-receptor pair may contribute to the establishment of distinct neural pathways by selectively inhibiting the neurite outgrowth and cell survival of mistargeted neurons. In addition, we show that ephrin-B2 expression is upregulated by cocaine and amphetamine in adult mice, suggesting that ephrin-B2/EphB1 interaction may play a role in drug-induced plasticity in adults as well.

Key words: axonal guidance; dopaminergic pathways; Eph family receptors; ephrins; drug addiction; plasticity

receptors (Zhou, 1998). This family is unique among tyrosine kinase receptors in that all of the ligands are membrane-anchored and in that the association is required for activity (Davis et al., 1994). The soluble ligands lack biological activity and can function as antagonists (Gao et al., 1996). The requirement of membrane anchorage makes the Eph family ligands uniquely qualified as local guidance cues for axonal targeting.

In vivo and in vitro observations indicate that the Eph family ligands and receptors play key roles in the specification of topographic projections. In the retinotectal and hippocamposeptal systems, Eph family ligands and receptors are expressed in projecting and target fields in opposing gradients (Cheng et al., 1995; Drescher et al., 1995; Gao et al., 1996; Zhang et al., 1996). Consistent with the expression patterns, ligand-receptor interactions repel and/or inhibit the growth of receptor-positive axons, thus contributing to the specification of topographic projection maps (Drescher et al., 1995; Gao et al., 1996, 1998; Nakamoto et al., 1996).

To examine the roles of the Eph family ligands and receptors in the development of the ascending midbrain dopaminergic pathways, we investigated the developmental expression of these guidance molecules in the dopaminergic neurons and their projection targets, including the caudate putamen, nucleus accumbens, and olfactory tubercle. We further examined the biological effects of the Eph ligands on dopaminergic neurons and their regulation by cocaine and amphetamine in vivo. Our studies indicate that the Eph family receptors and ligands may play important roles in regulating the formation of distinct dopaminergic pathways and may contribute to drug-induced neural plasticity.

\section{MATERIALS AND METHODS}

Animals and preparation of tissue sections. CD-1 mice from embryonic day (E) 14 to postnatal day (P) 60 (adult) were used in in situ hybridization experiments. The day of vaginal plug occurrence was defined as E1 and 
Table 1. Expression of Eph family receptors in the P7 midbrain dopamine neurons

\begin{tabular}{llllllllll} 
& \multicolumn{2}{l}{ Eph receptor } \\
\cline { 2 - 9 } Midbrain region & EphA3 & EphA4 & EphA5 & EphA6 & EphA7 & EphA8 & EphB1 & EphB2 & EphB3 \\
\hline SN & - & - & ++ & - & - & - & +++ & - & - \\
VTA & - & - & ++ & - & - & - & \pm & - & - \\
\hline
\end{tabular}

-, Expression below detection; \pm , low expression; ++ , moderate expression; +++ , strong expression.

the day of birth as P1. At least three animals were investigated at each age group. Whole embryos and brains of postnatal mice were dissected under carbon dioxide anesthesia and frozen on dry ice. Coronal and sagittal sections of $16 \mu \mathrm{m}$ thickness were cut on a cryostat at $-23^{\circ} \mathrm{C}$ and mounted on slides coated with $2 \%$ triethoxy-3-aminopropyl saline (Sigma, St. Louis, MO). Then the slides were stored at $-80^{\circ} \mathrm{C}$ before use.

In situ hybridization. mRNA expression was detected with either $\left[{ }^{35} \mathrm{~S}\right]-$ labeled in vitro transcribed riboprobes or end-labeled oligonucleotide probes. In situ hybridization was performed as described (Zhang et al., 1997). The optimal exposure time of hybridized sections to autoradiographic emulsion was determined by exposing the sections to x-ray film for various time periods before dipping. For quantitative in situ hybridization, complete sets of brain sections from different age or treatment groups were analyzed in the same experiment with the same probe. Different samples were compared only within the same experiment.

Developmental expression of nine Eph family tyrosine kinase receptors was investigated via in situ hybridization. Only EphB1 showed specific differential expression in the midbrain dopaminergic neurons. EphB1 mRNA was detected with a riboprobe transcribed in vitro from a $2.4 \mathrm{~kb}$ mouse EphB1 cDNA containing most of the coding region cloned in a pBluescript SK plasmid. Antisense riboprobe was synthesized with T7 RNA polymerase for hybridization, and a sense control probe was generated with T3 RNA polymerase. The synthesized riboprobes were hydrolyzed to smaller fragments $(\sim 0.2 \mathrm{~kb})$ by $0.2 \mathrm{M}$ bicarbonate at $60^{\circ} \mathrm{C}$ for $41.6 \mathrm{~min}$ before hybridization.

To examine the expression of the ligands of EphB1, we performed in situ hybridization analyses with probes of all three ephrin-B ligands. Only ephrin-B2 showed differential expression in the dopaminergic target fields. Ephrin-B2 mRNA was detected with a riboprobe made from a $1 \mathrm{~kb}$ human ephrin-B2 cDNA containing the full coding region in pBluescript $\mathrm{SK}^{-}$. Human ephrin-B2 has a $93 \%$ homology with mouse ephrin-B2 in the nucleotide level (Bergemann et al., 1995; Cerretti et al., 1995).

Quantitative analysis of EphB1 hybridization signals in the midbrain dopamine system and of ephrin-B2 signals in the striatum was performed with ImagePro 1.3 image analysis software. To avoid bias introduced by the variations of cell density in different regions, we quantitated only areas with comparable cell density for silver grain density, expressed as a percentage of the area covered by silver grains (area fraction analysis). For each experimental group, hybridization and measurements were done on three animals and on both sides of the regions of interest over multiple sections covering the entire anterior-posterior extension.

6-Hydroxydopamine treatment. Five late-pregnant CD-1 mice obtained from Charles River Laboratories (Wilmington, MA) were housed individually in pan cages until pups were born. On day 3 of life, pups in all groups were given a subcutaneous injection of $25 \mathrm{mg} / \mathrm{kg}$ pargyline plus 25 $\mathrm{mg} / \mathrm{kg}$ imipramine (Sigma). Under surgical anesthesia $60 \mathrm{~min}$ later the pups were injected in the left ventricle with 50 or $100 \mu \mathrm{g}$ of 6-hydroxydopamine base dissolved in $5 \mu \mathrm{l}$ of $0.1 \%$ ascorbic acid. On day 6 the procedure was repeated with the same dose in the right ventricle. Ventricle position was determined as $\pm 1.0 \mathrm{~mm}$ medial/lateral from bregma and $-2.5 \mathrm{~mm}$ ventral to the skull surface. Pups then were allowed to recover for $10 \mathrm{~d}$, at which time they were killed. For EphB1 in situ hybridization analysis the whole brain was dissected and frozen on dry ice. For neurochemical analysis, separate animals were killed, and the striatum was dissected and frozen in liquid nitrogen until assay.

Levels of dopamine and the metabolites dihydroxyphenylacetic acid (DOPAC) and homovanillic acid (HVA) were determined by using HPLC, as described previously (Halladay et al., 1998).

Construction of ephrin-B2-expressing cell line. Human full-length ephrin-B2 was cloned into a retroviral vector pLIG, which contains a $\beta$-galactosidase gene fused to an aminoglycoside phosphotransferase for G418 resistance (Lillian, 1996). Then the construct was transfected into National Institutes of Health-3T3 (NIH-3T3) cells. G418-resistant colonies were screened for ephrin-B2 expression, using immunocytochemical staining with polyclonal anti-ephrin-B2 antibody (Santa Cruz, CA). Positive stainings were found in the ephrin-B2-transfected cells. In contrast, no significant staining was observed in parental or vector-transfected NIH-3T3 cells.

Neuron culture and staining. The substantia nigra and ventral tegmental area of E18 rat embryos were dissected from the lateral two-thirds and the medial one-third of the ventral mesencephalon, respectively, under a microscope in PBS. The precise positions of substantia nigra and ventral tegmental area were determined by tyrosine hydroxylase $(\mathrm{TH})$ immunohistochemical staining of E18 rat midbrain sections. Neurons then were dissociated and cocultured with monolayer control NIH-3T3 cells or ephrin-B2-expressing fibroblasts in DMEM supplemented with fetal bovine serum $(10 \%)$, penicillin $(50 \mathrm{U} / \mathrm{ml})$, and streptomycin $(50 \mu \mathrm{g} / \mathrm{ml})$. Neurons were cultured for various times and stained with a monoclonal anti-TH antibody (Chemicon, Temecula, CA). The number of neurons and the lengths of neurites were measured with a Zeiss Telaval 31 microscope (Oberkochen, Germany). For quantitation of each sample, 20 random fields were chosen from top to bottom and from the left to right sides of culture wells to represent the entire culture.

Drug treatment. From 30 to $180 \mathrm{mg} / \mathrm{kg}$ body weight of cocaine or $\mathrm{D}$-amphetamine was injected subcutaneously in the neck of mice in four divided doses over $6 \mathrm{hr}$. The mice were killed $6 \mathrm{hr}$ or 1, 4, 7, or $14 \mathrm{~d}$ after treatment, and the expression of ephrin-B2 in the striatum was analyzed with in situ hybridization.

\section{RESULTS}

\section{Expression of Eph family receptor EphB1 in the midbrain dopaminergic neurons}

To examine the roles of the Eph family receptors in the development of the midbrain dopaminergic system, we investigated the expression of nine Eph family receptors that have been shown to be transcribed in the nervous system (for review, see Zhou, 1998), using in situ hybridization in P7 mouse brain. These studies showed that seven Eph receptors, EphA3, EphA4, EphA6, EphA7, EphA8, EphB2, and EphB3, were not expressed at significant levels in the midbrain dopaminergic neurons (Table 1). One receptor, EphA5, was transcribed at moderate levels in both the substantia nigra and the ventral tegmental area, consistent with a previous report (Maisonpierre et al., 1993) (Table 1). Only the remaining receptor, EphB1, was transcribed differentially in the ventral mesencephalon (Fig. 1). EphB1 expression was restricted primarily to the substantia nigra. Few transcripts were detected in the ventral tegmental area. Although thionine staining showed a comparable cell density (Fig. $1 A$ ), the hybridization signals were significantly higher $(\sim 4.8$-fold $)$ in the substantia nigra than in the ventral tegmental area (Figs. $1 B, 2$ ). The difference in EphB1 expression was not attributable to the lack of dopaminergic neurons in the ventral tegmental area, because TH immunohistochemical staining using neighboring serial sections showed that the enzyme was found in both the substantia nigra and the ventral tegmental area (Fig. 1C).

To demonstrate further that the Eph receptor was expressed in the dopaminergic neurons, we examined the levels of EphB1 expression in neonatal mice treated with 6-hydroxydopamine, 

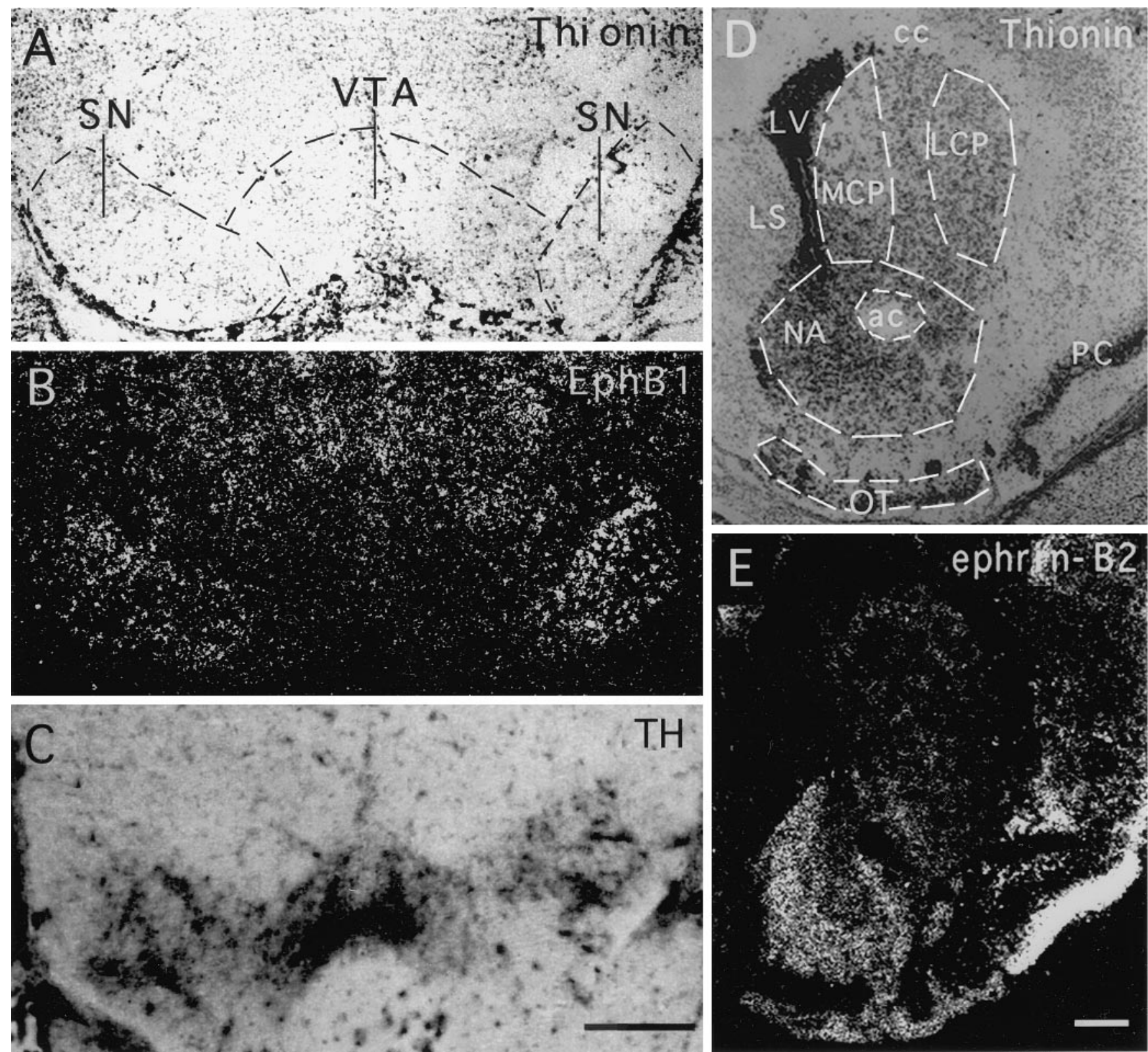

Figure 1. Complementary expression of the Eph family receptor EphB1 and ligand ephrin-B2 in the ascending mesencephalic dopamine systems. A, B, Bright- and dark-field photomicrographs, respectively, of a coronal section of a P2 mouse brain through the ventral mesencephalon hybridized with an antisense EphB1 probe. Hybridized sections were counterstained with thionine to identify the histological patterns. $C$, Photomicrograph of a neighboring section stained with anti-tyrosine hydroxylase (TH) immunocytochemistry to reveal the substantia nigra and ventral tegmental area. Note that TH staining was observed in both the substantia nigra and the ventral tegmental area, indicating the presence of dopaminergic neurons in both areas. $D$, $E$, Bright- and dark-field photomicrographs, respectively, of a P7 coronal mouse brain section through the striatum hybridized with an antisense ephrin-B2 riboprobe and counterstained with thionine. The circled areas are quantitated in Figure 2. $a c$, Anterior commissure; $c c$, corpus callosum; $L C P$, lateral caudate putamen; $L S$, lateral septum; $L V$, lateral ventricle; $M C P$, medial caudate putamen; $N A$, nucleus accumbens; $O T$, olfactory tubercle; $P C$, piriform cortex; $S N$, substantia nigra; $V T A$, ventral tegmental area. Scale bars, $0.46 \mathrm{~mm}$.

which selectively destroys dopamine neurons (Stodgell et al., 1998). The extent of lesion was confirmed by significant decreases in the levels of dopamine and its metabolites, DOPAC and HVA, in the striatum (Fig. 3A). In situ hybridization analysis showed that the decrease in the levels of dopamine and its metabolites was paralleled by a decrease in EphB1 expression levels in the substantia nigra (Fig. 3B). Thus, EphB1 mRNA is transcribed selectively in the substantia nigra dopaminergic neurons. The expression was observed in E18, the earliest stage examined in this study, and persists through adult, although higher levels were found from E18 to P7 (Table 2).

\section{Expression of Eph family ligand ephrin-B2 in the striatum}

EphB1-positive substantia nigra neurons are known to project to the caudate putamen, but not to the nucleus accumbens and olfactory tubercle. In contrast, the EphB1-negative ventral tegmental area dopaminergic neurons project primarily to the nu- 


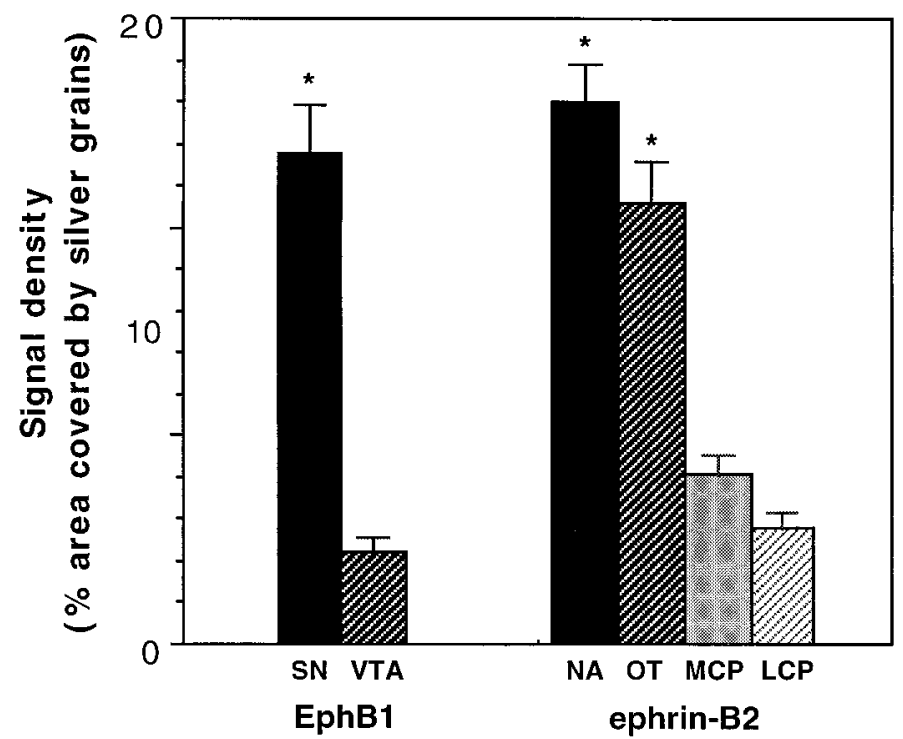

Figure 2. Quantitation of the expression of EphB1 in the midbrain and ephrin-B2 in the striatum. The areas quantitated are indicated in Figure 1. The data presented are the averages of expression levels from three different animals ( \pm SEM; ${ }^{*} p<0.02$; ANOVA). $L C P$, Lateral caudate putamen; $M C P$, medial caudate putamen; $N A$, nucleus accumbens; $O T$, olfactory tubercle; $S N$, substantia nigra; $V T A$, ventral tegmental area.

cleus accumbens and olfactory tubercle. To test the possibility that the receptor EphB1 and its ligands contribute to target specificity of the midbrain dopaminergic neurons, we examined the expression patterns of all of the ephrin-B subclass ligands, ephrin-B1 to ephrin-B3, in the target regions of these neurons. In situ hybridization studies showed that only ephrin-B2 was expressed at high levels in the striatum. The highest levels of expression were detected in the nucleus accumbens and olfactory tubercle (the ventromedial striatum) (see Figs. 1D,E, 2). Only very low levels were found in the caudate putamen. Thus, ephrin-B2 mRNA was differentially expressed in the striatum. Ephrin-B2 expression in the ventromedial striatum was detected at low levels at E18 to P1 and reached the highest level at approximately P7 (Table 2). Low levels of expression persisted in adult (Table 2). These observations indicate that ephrin-B2 expression is complementary to that of EphB1, suggesting that the ligand-receptor interaction may restrict the substantia nigra dopaminergic neurons from projecting to the ligand-rich areas, such as the nucleus accumbens and olfactory tubercle.

Ephrin-B2 selectively inhibits neurite outgrowth of the substantia nigra, but not the ventral tegmental area, dopaminergic neurons

The hypothesis that negative interaction between EphB1 and ephrin-B2 serves to restrict substantia nigra dopaminergic neurons from projecting to nucleus accumbens is consistent with known functions of the Eph ligands. This hypothesis predicts that axonal growth from substantia nigra, but not from the ventral tegmental area, is inhibited by ephrin-B2. To test this prediction, we examined the effect of ephrin-B2 on dopaminergic neurite outgrowth with a coculture assay. In this assay, ephrin-B2 was stably expressed on the surface of NIH-3T3 cells, because the biologically active ligands require membrane anchorage. Dopaminergic neurons from the substantia nigra and ventral tegmental area of E18 rat embryonic brain were dissected and overlaid on a confluent monolayer of control or ephrin-B2-expressing cells.
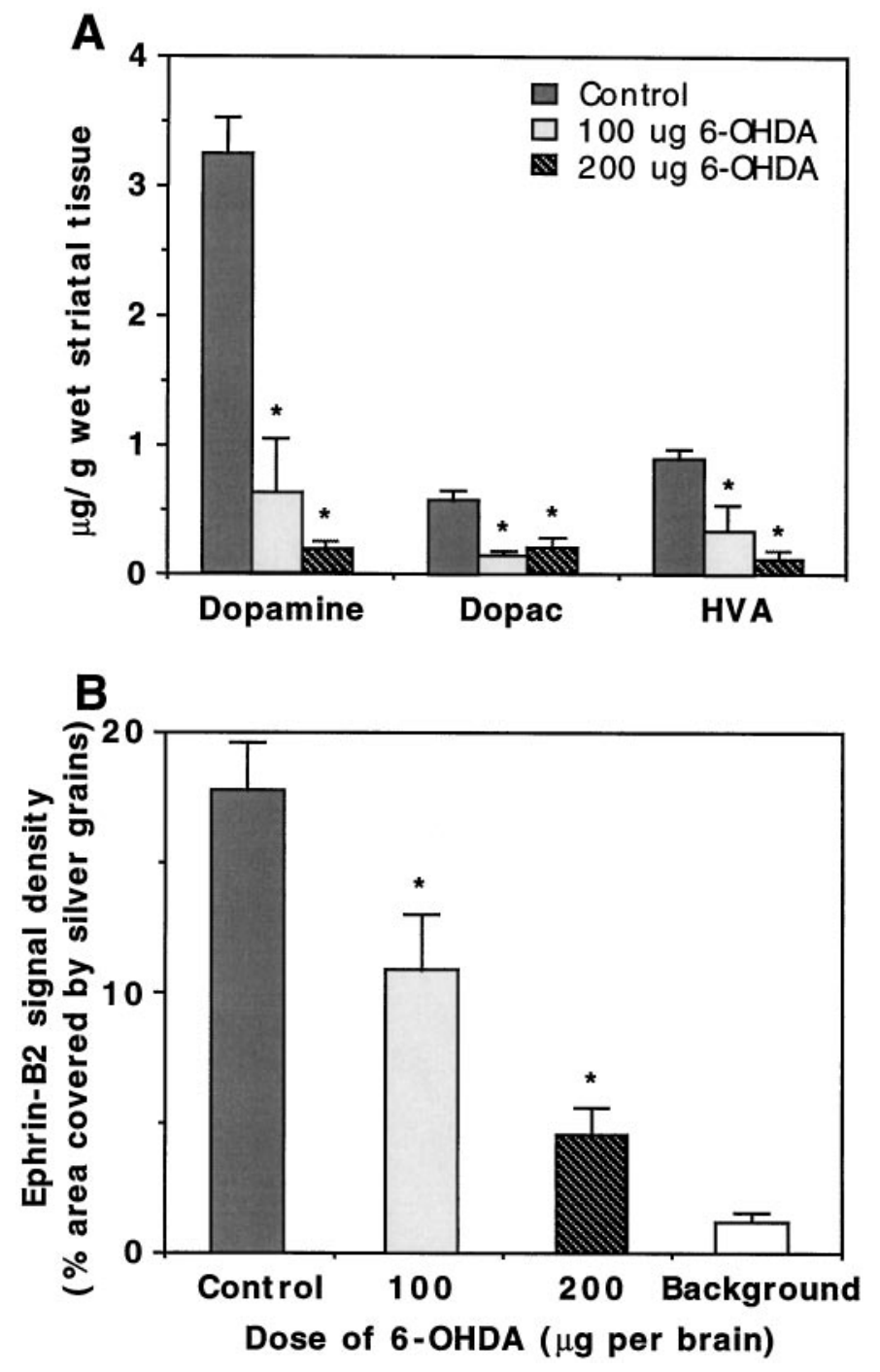

Figure 3. Reduction of EphB1 expression in the substantia nigra by 6-hydroxydopamine. $A$, Reduction of the levels of dopamine and the metabolites (DOPAC and $H V A$ ) in the striatum of 6-hydroxydopaminelesioned mice. The data collected are from two animals for each treatment. $B$, Reduction of EphB1 hybridization signals in the 6-hydroxydopamine-lesioned substantia nigra. The experiments were repeated three times, and two animals were used in each experiment. ${ }^{*} p<$ 0.02 ; ANOVA.

Dopaminergic neurons were detected with $\mathrm{TH}$ immunocytochemical staining after $2 \mathrm{~d}$ in culture. These studies showed that the ventral tegmental dopaminergic neurons grew long neurites on both the control and the ephrin-B2-expressing cells (Fig. $4 A, B)$. However, neurite outgrowth from substantia nigra dopaminergic neurons was reduced significantly on ephrin-B2expressing cells (Fig. 4C), although these neurons grew well on the control cells (Fig. 4D). The average neuritic length of the substantia nigra neurons on ephrin-B2 cells was only $50 \%$ of that on control cells (Fig. 5A). The inhibition was observed throughout the length distribution; for example, $>70 \%$ of substantia nigra axons on control cells were longer than $100 \mu \mathrm{m}$. In contrast, only $\sim 19 \%$ of the substantia nigra axons were longer than $100 \mu \mathrm{m}$ when they were cocultured with ephrin-B2-expressing cells (data not shown). No significant inhibition on ventral tegmental dopaminergic neurite outgrowth was observed (Fig. 5A). 
Table 2. Developmental expression of EphB1 and ephrin-B2 in the ascending midbrain DA systems

\begin{tabular}{|c|c|c|c|c|c|c|}
\hline \multirow[b]{2}{*}{ Stages } & \multicolumn{2}{|c|}{ EphB1 in the midbrain } & \multicolumn{4}{|c|}{ Ephrin-B2 in the striatum } \\
\hline & $\mathrm{SN}$ & VTA & NA & OT & $\mathrm{MCP}$ & LCP \\
\hline E18 & +++ & + & \pm & - & \pm & - \\
\hline $\mathrm{P} 1$ & +++ & + & + & + & \pm & - \\
\hline P3 & +++ & + & ++ & + & + & - \\
\hline $\mathrm{P} 7$ & +++ & \pm & +++ & ++ & ++ & + \\
\hline Adult & + & - & + & ++ & + & \pm \\
\hline
\end{tabular}

E, Embryonic stage; P, postnatal stage; DA, dopamine; SN, substantia nigra; NA, nucleus accumbens; OT, olfactory tubercle; MCP, medial caudate/putamen; LCP, lateral caudate putamen.
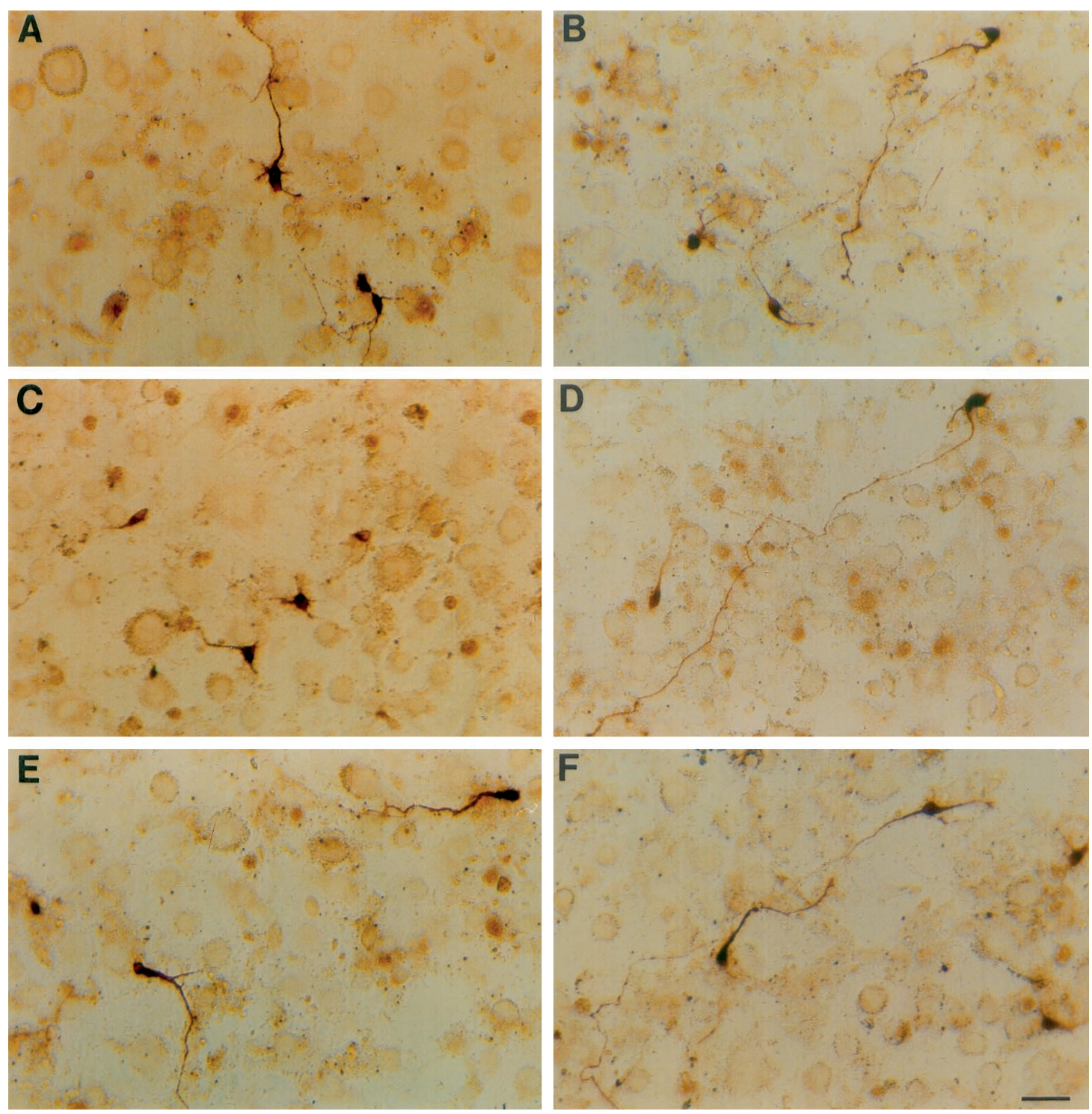

Figure 4. Ephrin-B2 inhibits the neurite outgrowth of rat E18 substantia nigra neurons. Medial (ventral tegmental area) or lateral (substantia nigra) mesencephalic dopaminergic neurons were dissected and cocultured with a confluent monolayer of ephrin-B2-expressing cells for 48 hr. Dopaminergic neurons were detected by immunocytochemical staining with an anti-TH antibody. $A, B$, Ventral tegmental dopaminergic neurons cocultured with ephrin-B2-expressing or control cells, respectively. $C$, $D$, Substantia nigra DA neurons cultured on the ephrin-B2-expressing or control cells, respectively. $E$, $F$, Substantia nigra dopaminergic neurons cultured on ephrin-B2-expressing or control cells in the presence of $6 \mu \mathrm{g} / \mathrm{ml}$ of ephrin-B2-Fc. Dopaminergic neurons are stained darkly. Ephrin-B2-expressing or control NIH-3T3 cells appear as faintly stained background. Scale bar, $30 \mu \mathrm{m}$. 


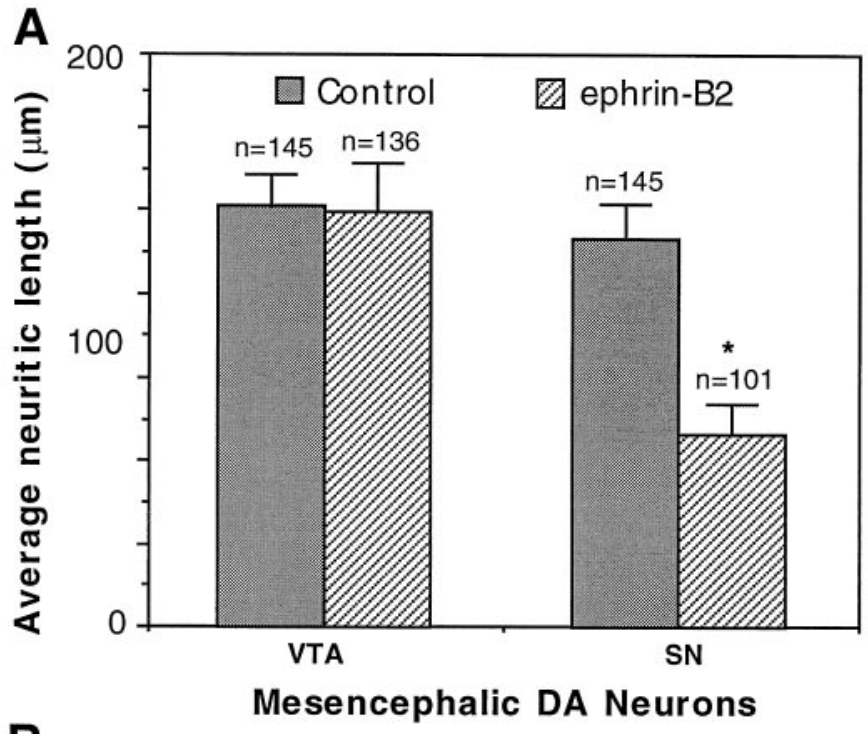

B

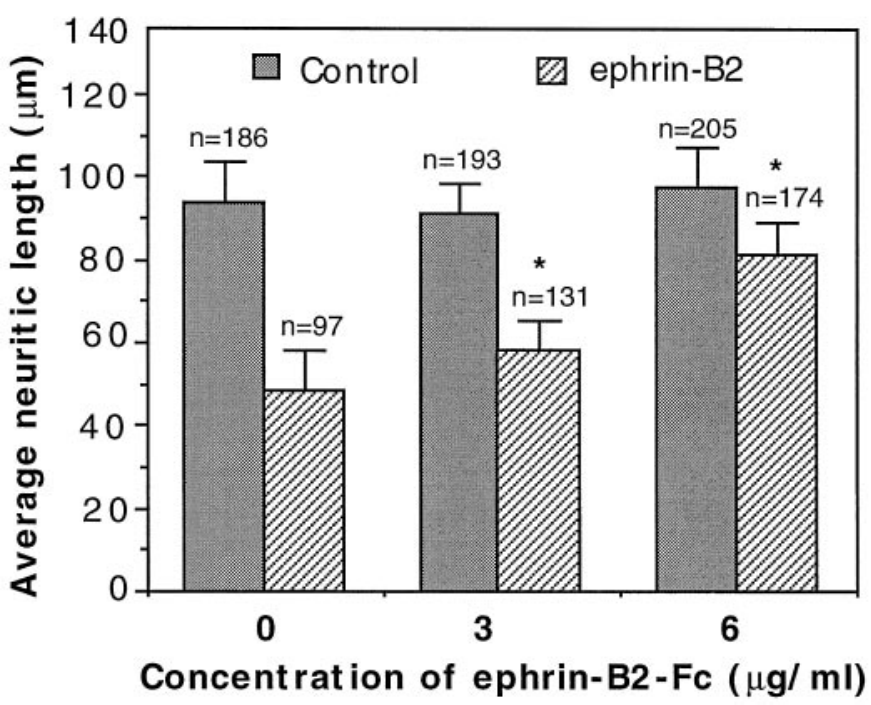

Figure 5. Quantitative analysis of ephrin-B2 effects on the mesencephalic dopaminergic neuritic outgrowth. $A$, Average neuritic length of the ventral tegmental $(V T A)$ and substantia nigra $(S N)$ dopaminergic neurons cocultured with ephrin-B2-expressing or control cells. The data shown are the averages of neuritic length $( \pm$ SEM $)$. The number of neurites quantitated is indicated above each column. Data were collected from six independent experiments. The difference in the neuritic length of substantia nigra neurons between the control and ephrin-B2-expressing cells is significant (Student's $t$ test; $p<0.005$ ). $B$, Soluble ephrin-B2 reduces the inhibitory effect on substantia nigra DA neurite outgrowth by ephrin-B2expressing cells. Dopaminergic neurons were cocultured with the ephrinB2-expressing cells in the presence of various concentrations of the soluble ligand as indicated. Neuritic length was measured and tabulated as in $A$. The data presented are from four independent experiments. Note that the soluble ligand increases the length of DA neurites in a dosedependent manner. ${ }^{*} p<0.001$; ANOVA.

It has been shown previously that soluble Eph ligands are antagonists for native membrane-bound ligands (Gao et al., 1996). To examine the specificity of inhibition, we added soluble ephrin-B2 to the coculture. The presence of soluble ligand reduced the inhibitive effects of ephrin-B2 on neurite outgrowth in a dose-dependent manner (Figs. $4 E, 5 B$ ). The presence of 6.0 $\mu \mathrm{g} / \mathrm{ml}$ soluble ephrin-B2 in large part reversed the inhibition on the substantia nigra neurite outgrowth by ephrin-B2, indicating that the inhibition is specific. Thus, the interaction between EphB1 and ephrin-B2 resulted in selective inhibition of neurite outgrowth from the substantia nigra dopaminergic neurons, which express high levels of EphB1, but had no effect on the ventral tegmental area neurons, which express only low levels of the receptor.

\section{Induction of cell loss of the substantia nigra dopaminergic neurons by ephrin-B2}

In addition to the inhibition of neurite outgrowth of the substantia nigra neurons, ephrin-B2 induced a significant decrease of the substantia nigra neuron number in the coculture (Fig. 6A). In the presence of ephrin-B2 the number of the tyrosine hydroxylasepositive substantia nigra neurons was only $41 \%$ of that in the control. However, there was no significant reduction in the number of ventral tegmental dopaminergic neurons when they were cocultured with ephrin-B2-expressing cells, as compared with control cells (Fig. 6A). The reduction in dopaminergic neuron number on ephrin-B2-expressing cells was not attributable to a decrease in adhesion, because the number was similar to the control after $12 \mathrm{hr}$ of coculture (Fig. 6B). However, significant neuron loss was apparent by $48 \mathrm{hr}$ of culture. By $72 \mathrm{hr}$, only $57 \%$ dopaminergic neurons survived, in comparison with an $80 \%$ survival rate on control cells (Fig. 6B). Furthermore, soluble ephrin-B2 increased the substantia nigra dopaminergic neuron number in a dose-dependent manner (Fig. 6C). To examine whether the decrease in cell number was attributable to apoptosis, we added methylated Boc-Asp-FMK (BAF; Enzyme System Products, Livermore, CA), a general caspase inhibitor, to the culture medium. BAF significantly increased both the survival rate and the neuritic length of the substantia nigra dopaminergic neurons (Fig. 7). These observations suggest that ephrin-B2 not only inhibits the growth of neurites from the substantia nigra dopaminergic neurons but also induces the loss of these neurons.

\section{Induction of ephrin-B2 expression in the striatum by addictive drugs}

Our observations indicate that ephrin-B2 and EphB1 may regulate the development of the ascending midbrain dopaminergic pathways by negatively regulating neurite outgrowth and survival of the EphB1-positive neurons in the substantia nigra. To examine potential roles in plasticity of the dopaminergic systems, we analyzed the effects of acute treatment of drugs of addiction. Subcutaneous injection of a total of $120 \mathrm{mg} / \mathrm{kg}$ cocaine or D-amphetamine dramatically induced ephrin-B2 expression in the striatum (Fig. 8). Ephrin-B2 induction by cocaine was dosedependent, reaching a saturation concentration at $120 \mathrm{mg} / \mathrm{kg}$ (total dose) (Fig. 9A). Quantitative analyses indicated that the induction appeared to be stronger in the nucleus accumbens, moderate in medial caudate putamen, and lowest in lateral caudate putamen (see Fig. 8D). The induction was evident by $6 \mathrm{hr}$ and reached the highest level by $24 \mathrm{hr}$ after injection (Fig. 9B). The level of ephrin-B2 decreased slowly as compared with that of the control over a period of $7 \mathrm{~d}$ after the first $24 \mathrm{hr}$. Similar results have been obtained with mice treated with amphetamine (see Fig. $8 D$ ). The ability of addictive drugs such as cocaine and amphetamine to induce the expression of ephrin-B2 indicates that the Eph family ligand also may play a role in plasticity of the adult midbrain dopaminergic pathways.

\section{DISCUSSION}

The current study has examined the roles of a specific Eph ligand and receptor in regulating the axonal growth of developing do- 

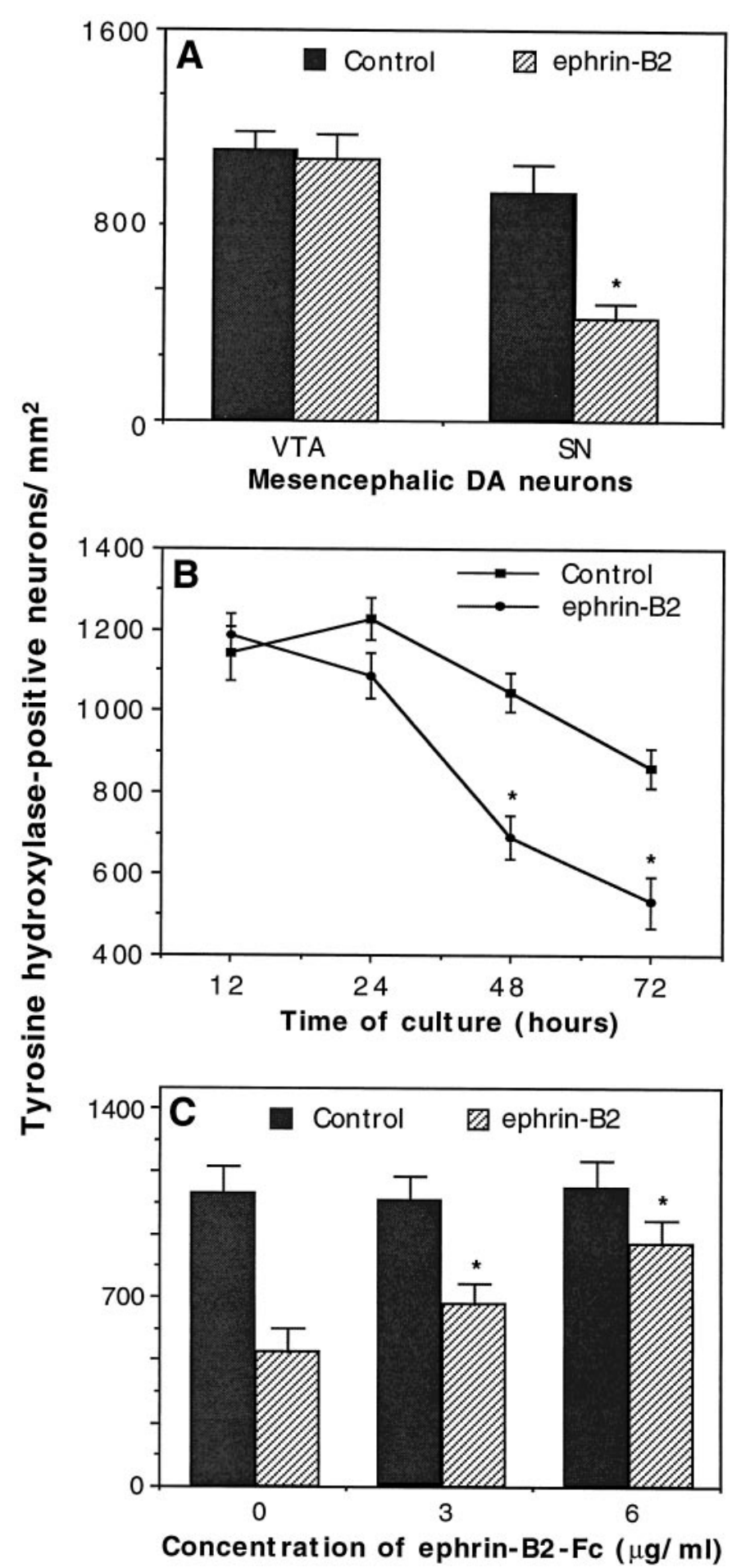

Figure 6. Selective induction of the cell death of the substantia nigra dopaminergic neurons by ephrin-B2. Ventral tegmental $(V T A)$ or substantia nigra $(S N)$ mesencephalic neurons were dissected and cocultured with control or ephrin-B2-expressing cells. After various times of coculture the cells were fixed and stained with anti-TH antibody to identify the dopaminergic neurons. A, Ephrin-B2 decreases the survival of the substantia nigra dopaminergic neurons. The cocultures were maintained for $48 \mathrm{hr}$ in this set of six experiments. The difference in the substantia nigra neuron number between control and ephrin-B2 cultures is significant; ${ }^{*} p<0.01$; Student's $t$ test. $B$, Time course of neuronal loss. The differences in the neuron number between control and ephrin-B2 cultures at 48 and $72 \mathrm{hr}$ are significant (three experiments; ${ }^{*} p<0.05$; Student's $t$ test). $C$, Inhibition of cell death by a specific ligand antagonist: the soluble form paminergic neurons from the ventral mesencephalon. Our results show that EphB1 and ephrin-B2 are transcribed in mutually exclusive patterns in different dopaminergic neuronal populations and their targets, constituting distinct neural pathways. Furthermore, ephrin-B2 specifically inhibits axonal growth and induces cell loss of the receptor-rich substantia nigra dopaminergic neurons while having no negative effects on the ventral tegmental area neurons. These observations indicate that ephrin-B2 may function to prevent the substantia nigra dopaminergic neurons from innervating the ligand-rich ventromedial striatum by inhibitory interactions, thus contributing to the specification of distinct neural pathways. We further report that addictive drugs, cocaine and amphetamine, induce ephrin-B2 expression in adult striatum. These observations together suggest that the Eph family ligand and receptor may participate both in the elaboration of dopaminergic circuits during development and in drug-induced plasticity in adult.

\section{EphB1 and ephrin-B2 expression and the ascending dopaminergic pathways}

A large body of evidence indicates that the mesolimbic pathway plays a key role in the motivational aspects of drug addiction as well as emotions and goal-oriented behavior in general (Koob, 1992; Self and Nestler, 1995; Hyman, 1996). In contrast, the nigrostriatal pathway appears to be essential for motor functions (Di Chiara et al., 1992), the degeneration of which is a hallmark of Parkinson's disease. The correlation of the topographic distribution of dopaminergic axon terminals in the striatum and the functional differentiation of the psychological and motor functions suggests that the topographic arrangement is critical to the functions of the midbrain dopaminergic systems.

Although it has been known for nearly 30 years that the ascending midbrain dopaminergic neurons project to their striatal targets in a topographic manner, the signals regulating the projection have not been identified. In this study we show that EphB1, a receptor of the Eph family, is expressed at high levels in the substantia nigra but at low levels in the ventral tegmental area. Complementary to EphB1 expression, ephrin-B2, a ligand of the receptor (Bergemann et al., 1995; Cerretti et al., 1995; Brambilla et al., 1996), is transcribed at high levels in the ventromedial region of the striatum, including the nucleus accumbens and olfactory tubercle, but at low levels in the dorsolateral striatum. Thus, substantia nigra dopaminergic neurons expressing high levels of the receptor EphB1 project to the dorsolateral striatum, which expresses low levels of the ligand ephrin-B2. Conversely, ventral tegmental neurons, which express low levels of the receptor, project to the ventromedial striatum, including the nucleus accumbens and the olfactory tubercle, where high levels of ephrin-B2 are transcribed (Fig. 10). The complementary expression of receptor and ligand in presynaptic and postsynaptic fields is reminiscent of the complementary expression of other Eph receptors and ligands in retinotectal system and hippocamposeptal system and is consistent with their known roles as negative guidance cues in topographic map formation (for review, see

$\leftarrow$

of ephrin-B2. Neurons were cocultured for $48 \mathrm{hr}$. The data presented represent the average of four different experiments ( \pm SEM). The differences among the number of TH-positive neurons cocultured with ephrinB2-expressing cells in the presence of 0,3 , or $6 \mu \mathrm{g} / \mathrm{ml}$ soluble ephrin-B2 are significant. ${ }^{*} p=0.001$; ANOVA. 
Pasquale 1997; Flanagan and Vanderhaeghen, 1998; Zhou, 1998) (also see Cheng et al., 1995; Drescher et al., 1995; Nakamoto et al., 1996; Monschau et al., 1997; Frisén et al., 1998).

\section{Ephrin-B2 regulates neurite outgrowth and cell survival of dopaminergic neurons}

The prediction of growth-inhibiting effects of ephrin-B2 on substantia nigra neurons that are EphB1-positive is supported by in vitro assays in this study. Neurite outgrowth of substantia nigra dopaminergic neurons is inhibited by ephrin-B2. In contrast, the growth of ventral tegmental dopaminergic neurons, which normally project to the ligand-rich nucleus accumbens and olfactory tubercle, is not affected. These observations provide further support to the notion that the ligands of the Eph family establish inhibitory domains in the nervous system to prevent inappropriate innervation (Drescher et al., 1995; Gao et al., 1996, 1998; Nakamoto et al., 1996; Monschau et al., 1997; Frisén et al., 1998).

Interestingly, in the coculture assay, ephrin-B2 also induces a significant loss of dopaminergic neurons from the substantia nigra, but not from the ventral tegmental area. There are at least two possible explanations for the cell loss. Reduction of cell number could be attributable to a decrease in adhesion because of the reduction in neuritic length by ephrin-B2. Alternatively, ephrin-B2 induces the death of substantia nigra dopaminergic neurons. We consider the first explanation unlikely for the following reasons: (1) at $12 \mathrm{hr}$ of culture the number of neurons on ephrin-B2-expressing and control cells is comparable, although neurites are very short at this time; (2) in our previous study (Gao et al., 1996), hippocampal neurons lacking neurites (because of inhibition by ephrin-A2) do not detach from underlying cells; (3) ventral spinal cord neurons undergo apoptotic cell death in the presence of ephrin-A5, as revealed by both cell counts and TUNEL labeling (Y. Yue and R. Zhou, unpublished data). Thus, the reduction of the number of substantia nigra dopaminergic neurons is likely attributable to cell death induced by ephrin-B2. Although much remains to be done to establish a role of ephrin-B2 in inducing apoptotic cell death, the fact that Boc-AspFMK (BAF), a general apoptosis inhibitor, increases cell survival is consistent with this proposal. Furthermore, the anti-apoptotic gene $b c l-2$ has been shown to promote axon regeneration (Chen et al., 1997), suggesting that molecules regulating cell death may regulate axonal growth also.

Earlier studies of the retinotectal development demonstrate that the maturation of the retinotectal map is accompanied by the death of retinal ganglia cells (Rager and Rager, 1976, 1978; Hughes and McLoon, 1979; McLoon and Lund, 1982; Jenkins and Straznicky, 1986). Although it has been proposed that an insufficient number of trophic factors present in the targets or the inability to form appropriate synaptic connections may be responsible for ganglion cell death (Hughes and McLoon, 1979), our observations raise the possibility that the interaction between the Eph ligands and receptors also may play a role in eliminating mistargeted cells during the development of topographic maps.

The timing of expression of the ligand-receptor pair is consistent with a function in establishing target specificity of dopaminergic neurons. Dopaminergic innervation occurs primarily in the first 4 postnatal weeks (Loizou, 1969, 1972; Coyle and Axelrod, 1972; Olson et al., 1972; Seiger and Olson, 1973). High differential expression of both the ligand and the receptor was observed in the
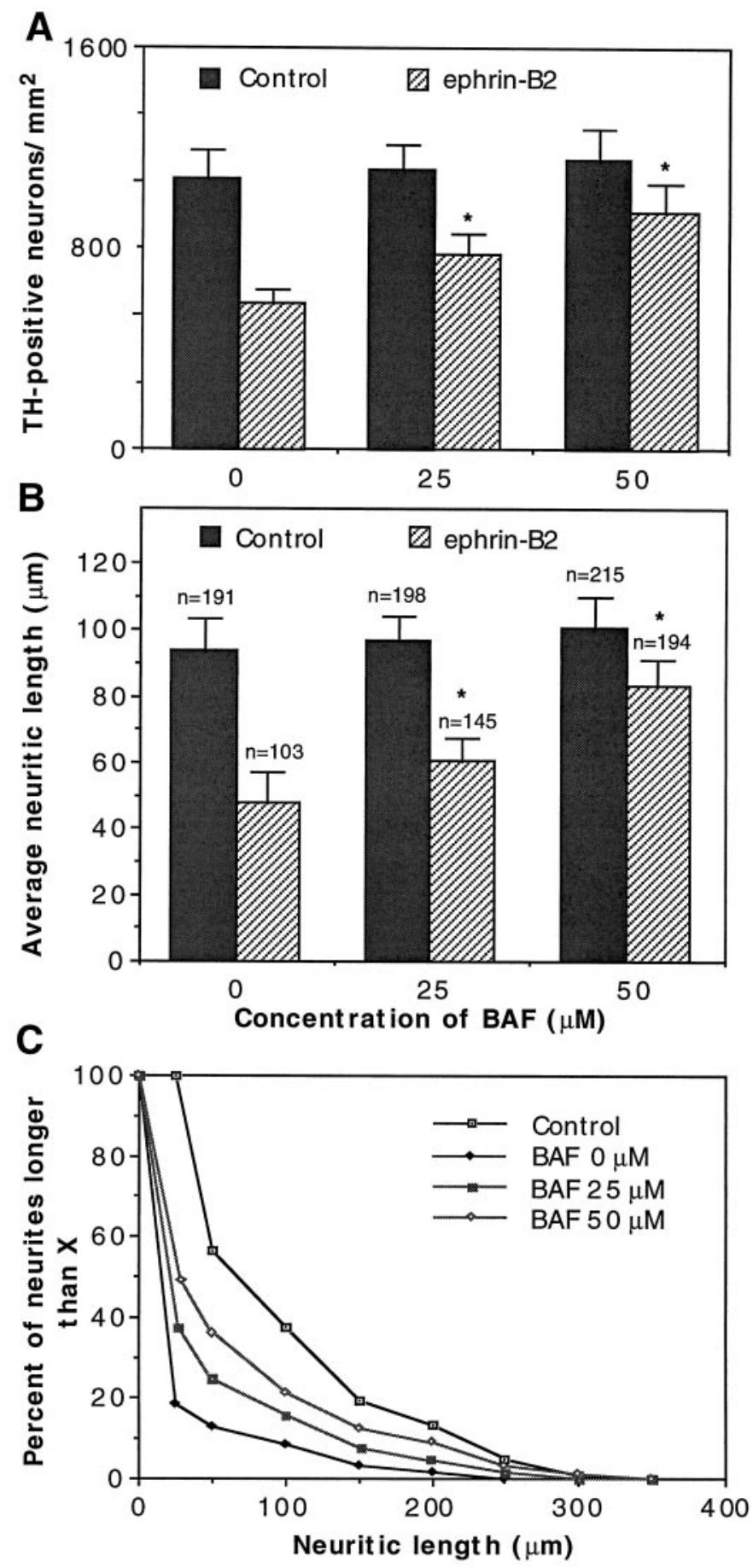

Figure 7. An apoptosis inhibitor, Boc-Asp-FMK (BAF), reduces the inhibitory effects of ephrin-B2. Substantia nigra DA neurons were cocultured with ephrin-B2-expressing cells or control NIH-3T3 cells in the presence of various concentrations of BAF. After $48 \mathrm{hr}$ of coculture the DA neurons were detected with anti-TH antibody and quantitated for the number of surviving neurons and the lengths of neurites. $A$, BAF increases the number of $\mathrm{TH}$-positive neurons. $B$, BAF increases the average neuritic length. The number of neurites quantitated is indicated above each column. $C$, Neuritic length distribution in the presence of BAF. The distribution was plotted with data from $B$. The Control represents the neurite length distribution of substantia nigra DA neurons grown on control-transfected NIH-3T3 cells. The absence of BAF $(0 \mu \mathrm{M})$ on ephrin-B2-transfected cells represents the condition in which the most potent inhibition of neurite outgrowth was obtained. The data presented are the average of three separate experiments. ${ }^{*} p<0.001$; ANOVA. 

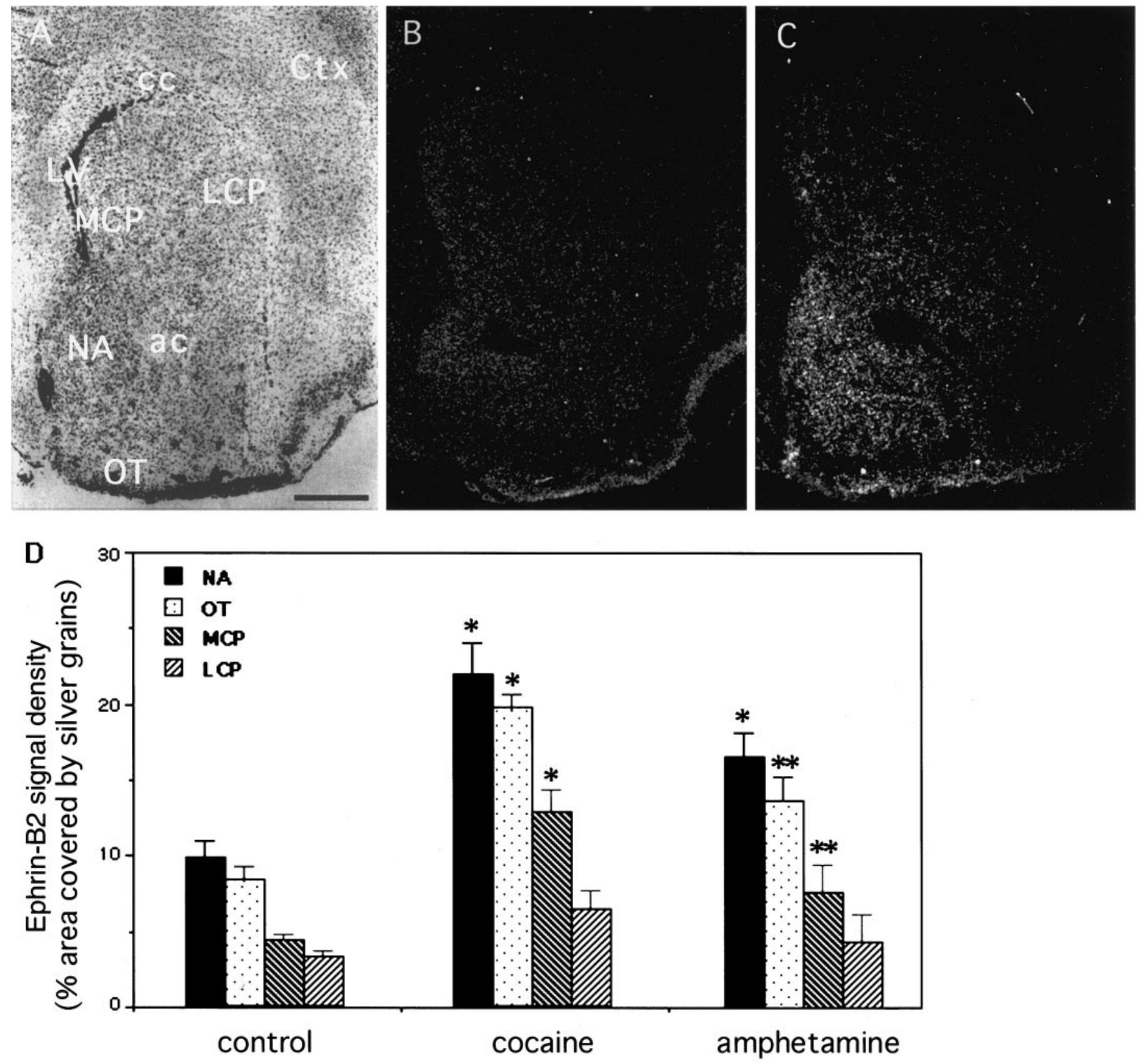

Figure 8. Induction of ephrin-B2 in the striatum by cocaine and amphetamine. Adult mice were injected subcutaneously with a total dose of $120 \mathrm{mg} / \mathrm{kg}$ cocaine or D-amphetamine. The mice were killed $24 \mathrm{hr}$ later and analyzed for ephrin-B2 expression with in situ hybridization. Four striatal areas, the nucleus accumbens $(N A)$, medial caudate putamen $(M C P)$, lateral $(L C P)$ caudate putamen, and the olfactory tubercle $(O T)$, were quantitated. $A$, $B$, Bright- and dark-field photomicrographs, respectively, of a control (saline-injected) adult mouse brain section through the striatum hybridized with an antisense ephrin-B2 probe. $C$, Dark-field photomicrograph of an ephrin-B2-hybridized section through the striatum of a cocaine-treated (24 hr after treatment at $120 \mathrm{mg} / \mathrm{kg}$ total dose) adult mouse brain. $D$, Quantitative analysis of ephrin-B2 induction by cocaine and amphetamine. The hybridization signals were measured for the percentage of the area covered by the silver grains. The data presented represent the average of three different animals in each experimental group. The areas quantitated are indicated in Figure $1 D$. The differences in signal density between control and drug-treated animals are significant. ${ }^{*} p<0.001 ;{ }^{*} p<0.05$; ANOVA. $a c$, Anterior commissure; $c c$ : corpus callosum; $C t x$, cerebral cortex; $L V$, lateral ventricle. Scale bar, $0.62 \mathrm{~mm}$.

early postnatal period, and peak ligand expression was found in the P7 nucleus accumbens (Table 2). Thus, ephrin-B2 and EphB1 may participate in the specification of distinct dopaminergic pathways by negatively regulating axonal growth and cell survival of substantia nigra dopaminergic neurons.

\section{Role of ephrin-B2 in drug-induced plasticity}

Our observations that ephrin-B2 is induced by acute administration of cocaine and amphetamine suggest that the Eph ligand may play a role in drug-induced plasticity. Addictive drugs such as cocaine, amphetamine, and heroin exert their rewarding effects of 


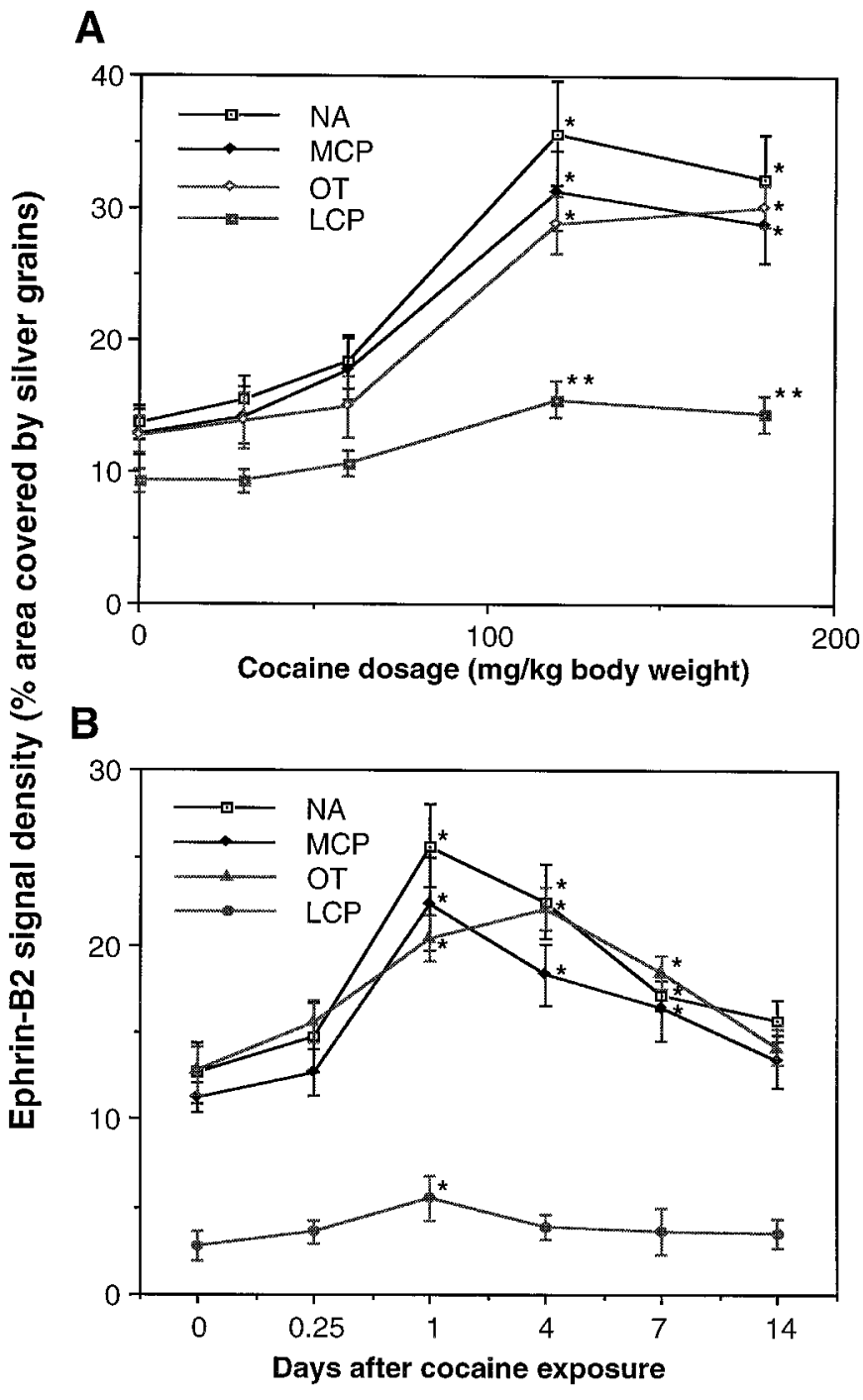

Figure 9. Dose-response and time course of ephrin-B2 induction by cocaine. $A$, Dose-response of ephrin-B2 induction. Different doses of cocaine $(30-180 \mathrm{mg} / \mathrm{kg}$ ) were injected subcutaneously (in four divided doses). At $24 \mathrm{hr}$ after injection the mice were killed and analyzed for ephrin-B2 expression, as in Figure 8. The nucleus accumbens showed the highest level of induction. $B$, Time course of ephrin-B2 induction. Mice treated with $120 \mathrm{mg} / \mathrm{kg}$ cocaine (total dose) were killed at various times, as indicated, for analysis of ephrin-B2 expression as in $A$. The data for each dose or time point represent the average of three different animals in the same treatment group. Animals for each experiment were examined in the same in situ analysis with the same riboprobe. $L C P$, Lateral caudate putamen; $M C P$, medial caudate putamen; $N A$, nucleus accumbens; $O T$, olfactory tubercle. ${ }^{*} p<0.001 ;{ }^{* *} p<0.005$; ANOVA.

euphoria and pleasure in part via interactions with the dopaminergic system. Cocaine, for example, acts by inhibiting the dopamine transporter and has no effects on knock-out mice lacking the transporter (Giros et al., 1996). It is thought that the reinforcing efficacy of drugs is derived by a release of dopamine into the accumbens, a notion supported by studies in which lesions are made or dopaminergic antagonists are injected in the accumbens (Roberts et al., 1980; Dworkin and Smith, 1987; Koob and Goeders, 1989; Koob, 1992; Robledo et al., 1992). The induction of ephrin-B2 by cocaine and amphetamine in the accumbens is consistent with a role in addiction.

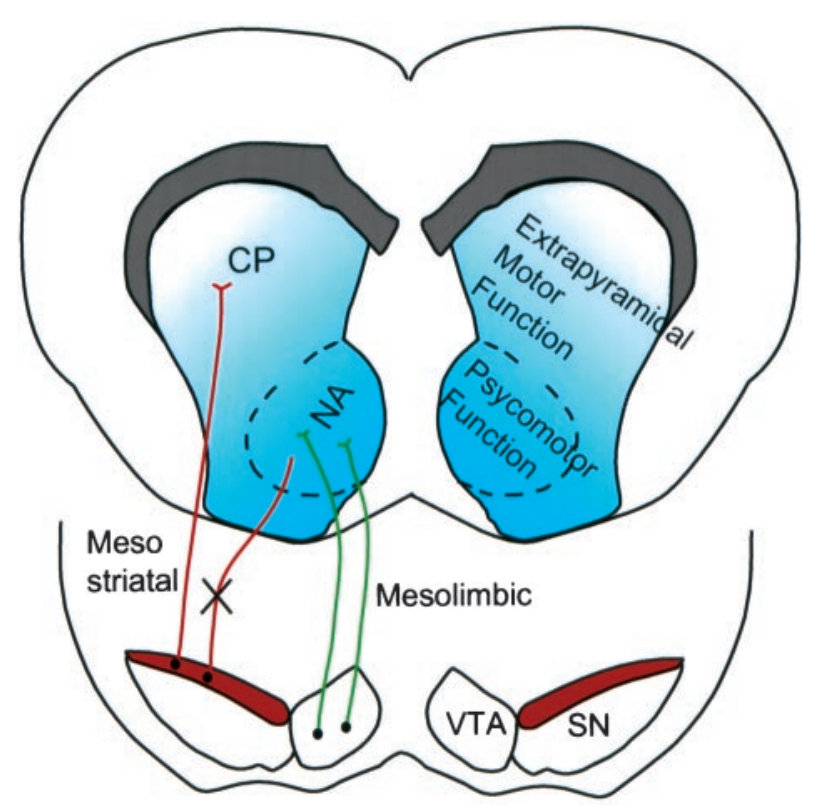

Figure 10. Schematic representation of the relationship between EphB1ephrin-B2 expression and the topographic projection pattern of midbrain dopaminergic neurons to the striatal targets. In the central dopaminergic system EphB1 was detected at high levels (shown in red) in the substantia nigra $(S N)$. In contrast, little expression was observed in the ventral tegmental system $(V T A)$, which also contains large numbers of dopaminergic neurons. Complementary to EphB1 expression, its ligand, ephrin$\mathrm{B} 2$, is expressed in the developing striatum at high levels (shown in blue) in the nucleus accumbens and olfactory tubercle, the ventromedial regions of the striatum, with only low levels of expression in the dorsolateral region, the caudate putamen $(C P)$. We hypothesized that the interaction between EphB1 and ephrin-B2 may result in an inhibitive signal (indicated by an $X$ ) to restrict substantia nigra axons from innervating the ventromedial striatum, thus contributing to the establishment of the mesostriatal and mesolimbic pathways.

Drug addiction is thought to reflect plastic changes in the neural circuitry mediating the effect of the drug (Nestler et al., 1993; Hyman, 1996). There are at least two basic mechanisms underlying plasticity in general. The first is biochemical changes in neurons and related circuits that, in turn, may lead to electrophysiological changes. For instance, upregulation of the cyclic AMP pathway has been considered a key event in adaptation to opiates in locus ceruleus and to cocaine in the nucleus accumbens (Nestler et al., 1993; Hyman, 1996). The second is structural changes of the synapses, neurons, or pathways involved. It has been shown that chronic morphine treatment reduces the size of ventral tegmental dopamine neurons (Sklair-Tavron et al., 1996). Growth of new synapses has been demonstrated in long-term memory, associated with rapid and transient modulations of molecules such as NCAM-related cell adhesion molecules, which also regulate axonal outgrowth and guidance in the developing nervous system (for review, see Bailey and Kandel, 1995).

Whether changes in neuronal connections are induced by drugs of abuse has not been examined. However, our observation that the Eph family ligand ephrin-B2 is upregulated in the dopamine targets by acute cocaine treatment suggests that modulation of the topographic projection of the dopamine system may be a novel mechanism of drug-induced plasticity. Consequently, the ephrinB2-EphB1 interaction may play a role in both the development and plasticity of the dopaminergic brain reward circuit. 


\section{REFERENCES}

Bailey CH, Kandel ER (1995) Molecular and structural mechanisms underlying long-term memory. In: Cognitive neuroscience (Gazzaniga MS, ed), pp 19-36. Cambridge, MA: MIT.

Beckstead RM, Domesick VB, Nauta WJH (1979) Efferent connections of the substantia nigra and ventral tegmental area in the rat. Brain Res 175:191-217.

Bergemann AD, Cheng HJ, Brambilla R, Klein R, Flanagan JG (1995) Elf-2, a new member of the Eph ligand family, is segmentally expressed in mouse embryos in the region of the hindbrain and newly forming somites. Mol Cell Biol 15:4921-4929.

Brambilla R, Bruckner K, Orioli D, Bergemann AD, Flanagan JG, Klein $\mathrm{R}$ (1996) Similarities and differences in the way transmembrane-type ligands interact with the elk subclass of Eph ligands. Mol Cell Neurosci 8:199-209.

Carter DA, Fibiger HC (1977) Ascending projections of presumed dopamine-containing neurons in the ventral tegmentum of the rat as demonstrated by horseradish peroxidase. Neuroscience 2:569-576.

Cerretti DP, Bos TV, Nelson N, Kozlosky CJ, Reddy P, Maraskovsky E, Park LS, Lyman SD, Copeland NG, Gilbert DJ, Jenkins NA, Fletcher FA (1995) Isolation of Lerk5: a ligand of the Eph-related receptor tyrosine kinases. Mol Immunol 32:1197-1205.

Chen DF, Schneider GE, Martinou JC, Tonegawa S (1997) Bcl-2 promotes regeneration of severed axons in mammalian CNS. Nature 385:434-439.

Cheng H-J, Nakamoto M, Bergemann AD, Flanagan JG (1995) Complementary gradients in expression and binding of ELF-1 and Mek4 in development of the topographic retinotectal projection map. Cell 82:371-381.

Coyle JT, Axelrod J (1972) Tyrosine hydroxylase in rat brain: developmental characteristics. J Neurochem 19:1117-1123.

Davis S, Gale NW, Aldrich TH, Maisonpierre PC, Lhotak V, Pawson T, Goldfarb M, Yancopoulos G (1994) Ligands for EPH-related receptor tyrosine kinases that require membrane attachment or clustering for activity. Science 266:816-819.

Di Chiara G, Morelli M, Acquas E, Carboni E (1992) Functions of dopamine in the extrapyramidal and limbic systems. Clues for the mechanism of drug actions. Arzneimittelforschung 42:231-237.

Drescher U, Kremoser C, Handwerker C, Loschinger J, Masaharu N, Bonhoeffer F (1995) In vitro guidance of retinal ganglion cell axons by RAGS, a $25 \mathrm{kDa}$ tectal protein related to ligands for Eph receptor tyrosine kinases. Cell 82:359-370.

Dworkin SI, Smith JE (1987) Neurobiological aspects of drug-seeking behaviors. Adv Biochem Pharmacol 6:1-43.

Fallon JH, Moore RY (1978) Catecholamine innervation of the basal forebrain. IV. Topography of the dopamine projection to the basal forebrain and neostriatum. J Comp Neurol 180:545-580.

Flanagan JG, Vanderhaeghen P (1998) The ephrins and Eph receptors in neural development. Annu Rev Neurosci 21:309-345.

Friedman GC, O'Leary DDM (1996) Eph receptor tyrosine kinases and their ligands in neural development. Curr Opin Neurobiol 6:127-133.

Frisén J, Yates PA, McLaughlin T, Friedman GC, O'Leary DDM, Barbacid M (1998) Ephrin-A5 (AL-1/RAGS) is essential for proper retinal axon guidance and topographic mapping in the mammalian visual system. Neuron 20:235-243.

Gao P-P, Zhang J-H, Yokoyama M, Racey B, Dreyfus CF, Black IB, Zhou R (1996) Regulation of topographic projection in the brain: Elf-1 in the hippocamposeptal system. Proc Natl Acad Sci USA 93:11161-11166.

Gao, PP, Yue Y, Zhang J-H, Cerretti DP, Levitt P, Zhou R (1998) Regulation of thalamic neurite outgrowth by the Eph ligand ephrin-A5: implications in the development of thalamocortical projections. Proc Natl Acad Sci USA 95:5329-5334.

Giros B, Jaber M, Jones SR, Wightman RM, Caron MG (1996) Hyperlocomotion and indifference to cocaine and amphetamine in mice lacking the dopamine transporter. Nature 379:606-612.

Halladay AK, Fisher H, Wagner GC (1998) Interaction of phentermine plus fenfluramine: neurochemical and neurotoxic effects. Neurotoxicology 19:177-184.

Harris WA, Holt CE (1995) From tags to RAGS: chemoaffinity finally has receptors and ligands. Neuron 15:241-244.

Heimer L, Zahm DS, Alheid GF (1995) Basal ganglia. In: The rat nervous system (Paxinos G, ed), pp 579-628. San Diego: Academic.

Hughes WF, McLoon SC (1979) Ganglion cell death during normal retinal development in the chick: comparisons with cell death induced by early target field destruction. Exp Neurol 66:587-601.

Hyman SE (1996) Addiction to cocaine, amphetamine. Neuron 16:901-904.

Jenkins S, Straznicky C (1986) Naturally occurring and induced ganglion cell death: a retinal whole-mount autoradiographic study in $\mathrm{Xe}$ nopus. Anat Embryol (Berl) 174:59-66.

Koob GF (1992) Drugs of abuse: anatomy, pharmacology, and function of reward pathways. Trends Pharmacol Sci 13:177-184.

Koob GF, Goeders NE (1989) Neuroanatomical substrates of drug selfadministration. In: The neuropharmacological basis of reward (Liebman JM, Cooper SJ, eds), pp 214-263. Oxford: Clarendon.

Lillian L (1996) Changes in retinal cell fate induced by overexpression of EGF receptor. Nature 377:158-162.

Lindvall O, Bjorklund A (1983) Dopamine- and norepinephrinecontaining neuron system: their anatomy in the rat brain. In: Chemical neuroanatomy (Emson PC, ed), pp 229-255. New York: Raven.

Loizou LA (1969) The development of monoamine-containing neurons in the brain of the albino rat. J Anat 104:588.

Loizou LA (1972) The postnatal ontogeny of monoamine-containing neurones in the central nervous system of the albino rat. Brain Res 40:395-418

Maisonpierre PC, Barrezueta NX, Yancopoulos GD (1993) Ehk-1 and Ehk-2: two novel members of the Eph receptor-like tyrosine kinase family with distinctive structures and neuronal expression. Oncogene 8:3277-3288.

McLoon SC, Lund RD (1982) Transient retinofugal pathways in the developing chick. Exp Brain Res 45:277-284.

Monschau B, Kremoser C, Ohta K, Tanaka H, Kaneko T, Yamada T, Handwerker C, Hornberger MR, Loschinger J, Pasquale EB, Siever DA, Verderame MF, Muller BK, Bonhoeffer F, Drescher U (1997) Shared and distinct functions of RAGS and ELF-1 in guiding retinal axons. EMBO J 16:1258-1267.

Moore RY, Bloom FE (1978) Central catecholamine neuron systems: anatomy and physiology of the dopamine systems. Annu Rev Neurosci 1:129-169.

Nakamoto M, Cheng H-J, Friedman GC, McLaughlin T, Hansen MJ, Yoon CH, O'Leary DDM, Flanagan JG (1996) Topographically specific effects of ELF-1 on retinal axon guidance in vitro and retinal axon mapping in vivo. Cell 86:755-766.

Nauta WJH, Smith GP, Faull M, Domesick VB (1978) Efferent connections and nigral afferents of the nucleus accumbens septi in the rat. Neuroscience 3:385-401.

Nestler EJ, Hope BT, Widnell KL (1993) Drug addiction: a model for the molecular basis of neural plasticity. Neuron 11:995-1006.

Olson L, Seiger A, Fuxe K (1972) Heterogeneity of striatal and limbic dopamine innervation: highly fluorescent islands in developing and adult rats. Brain Res 44:283-288.

Orioli D, Klein R (1997) The Eph receptor family: axonal guidance by contact repulsion. Trends Genet 13:354-359.

Pasquale EB (1997) The Eph family of receptors. Curr Opin Cell Biol 9:608-615.

Rager G, Rager U (1976) Generation and degeneration of retinal ganglion cells in the chicken. Exp Brain Res 25:551-553.

Rager G, Rager U (1978) System matching by degeneration. I. A quantitative electron microscopic study of the generation and degeneration of retinal ganglion cells in the chicken. Exp Brain Res 33:65-78.

Roberts DC, Koob GF, Klonoff P, Fibiger HC (1980) Extinction and recovery of cocaine self-administration following 6-hydroxydopamine lesions of the nucleus accumbens. Pharmacol Biochem Behav 12:781-787.

Robledo P, Maldonado-Lopez R, Koob GF (1992) Role of dopamine in the nucleus accumbens in the rewarding properties of cocaine. Ann NY Acad Sci 654:509-512.

Seiger A, Olson L (1973) Late prenatal ontogeny of central monoamine neurons in the rat: fluorescence histochemical observations. Z Anat Entwicklungsgesch 140:281-318.

Self DW, Nestler EJ (1995) Molecular mechanisms of drug reinforcement and addiction. Annu Rev Neurosci 18:463-495.

Simon H, Le Moal M, Galey D, Cardo B (1976) Silver impregnation of dopaminergic systems after radiofrequency and 6-OHDA lesions of the rat ventral tegmentum. Brain Res 115:215-231.

Simon H, Le Moal M, Calas A (1979) Efferents and afferents of the ventral tegmental-A10 region studied after local injection of $\left[{ }^{3} \mathrm{H}\right]$ leucine and horseradish peroxidase. Brain Res 178:17-40. 
Sklair-Tavron L, Shi W-X, Lane SB, Harris HW, Bunney BS, Nestler EJ (1996) Chronic morphine induces visible changes in the morphology of mesolimbic dopamine neurons. Proc Natl Acad Sci USA 93:11202-11207.

Stodgell CJ, Loupe PS, Schroeder SR, Tessel RE (1998) Crosssensitization between footshock stress and apomorphine on selfinjurious behavior and neostriatal catecholamines in a rat model of Lesch-Nyhan syndrome. Brain Res 783:10-18.

Tessier-Lavigne M (1995) Eph receptor tyrosine kinases, axon repulsion, and the development of topographic maps. Cell 82:345-348.

Ungerstedt U (1971) Stereotaxic mapping of the monoamine pathways in the rat brain. Acta Physiol Scand Suppl 367:1-48.

van der Kooy D (1979) The organization of the thalamic, nigral, and raphe cells projecting to the medial vs lateral caudate putamen in rat. A fluorescent retrograde double-labeling study. Brain Res 169:381-387.

Zhang J-H, Cerretti DP, Yu T, Flanagan JG, Zhou R (1996) Detection of ligands in regions anatomically connected to neurons expressing the Eph receptor Bsk: potential roles in neuron-target interaction. J Neurosci 16:7182-7192.

Zhang J-H, Pimenta AF, Levitt P, Zhou R (1997) Dynamic expression suggests multiple roles of the Eph family receptor brain-specific kinase (Bsk) during mouse neurogenesis. Brain Res Mol Brain Res 47:202-214.

Zhou R (1998) The Eph family receptors and ligands. Pharmacol Ther 77:151-181. 